\title{
Was färbte die Zunge schwarz?
}

- Ein 24-jähriger Mann kam mit Halsschmerzen in die Sprechstunde. Besonders beunruhigte ihn aber eine Schwarzfärbung am Zungengrund. Wegen eines Infekts der oberen Luftwege hatte er in der vorangegangenen Woche Ciprofloxacin und Doxycyclin eingenommen. Er war Nichtraucher und benutzte auch keinen Kautabak. Auch nahm er keine wismuthaltigen Medikamente ein.

Bei der Untersuchung erkannte man weißliche Beläge der Zunge und eine schwarze Verfärbung des Zungengrundes. Fieber, Lymphknotenvergrößerungen oder eine Hepatosplenomegalie wurden nicht festgestellt. Schnelltests auf Streptokokkenantigen und Mononukleose fielen negativ aus. Im Rachenabstrich konnte Candida albicans nachgewiesen werden.
Die schwarze Haarzunge (Lingua villosa nigra) tritt auf in Anwesenheit chromogener Mikroorganismen, zum Beispiel Candida albicans und bei Verwendung bestimmter Medikamente, zum Beispiel Doxycylin oder Wismut. Allerdings ist nicht bekannt, ob Doxycyclin und Candida albicans im Hinblick auf die Verfärbung der Zungenpapillen synergistisch wirken. Man nimmt an, dass es zunächst zu einer Proliferation der filiformen Zungenpapillen kommt, die mit porphyrinproduzierenden chromogenen Bakterien oder Hefen schwarz eingefärbt werden. Doxycylin wurde abgesetzt und der Patient über kurze Zeit hinweg mit Fluconazol behandelt. Die schwarze Verfärbung und die haarige Oberfläche der Zunge verschwanden innerhalb von drei Tagen.

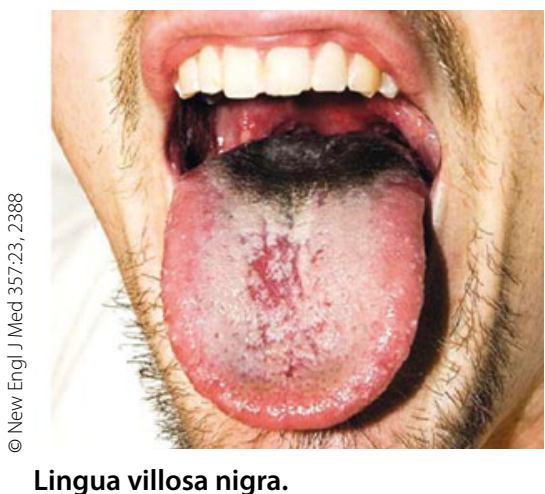

Mit der sorgfältigen Erhebung der Anamnese und der richtigen Blickdiagnose konnten in diesem Fall unnötige Maßnahmen vermieden und dem $\mathrm{Pa}$ tienten rasch geholfen werden.

H. S. FÜESSL

- A. Ramsakal, L. Mangat
Lingua villosa nigra. New Engl. J. Med. 357:23,
2388 